This paper has been accepted for publication in Trends of Plant Science and has been published online on April 10, 2015, http://www.sciencedirect.com/science/article/pii/S1360138515000771 doi: 10.1016/j.tplants.2015.03.011

\title{
Fatal attraction: The intuitive appeal of GMO opposition
}

Stefaan Blancke ${ }^{1}$, Frank Van Breusegem ${ }^{2,3}$, Geert De Jaeger ${ }^{2,3}$, Johan Braeckman ${ }^{1}$ and Marc Van Montagu $^{2,3,4}$

${ }^{1}$ Department of Philosophy and Moral Sciences, Ghent University, 9000 Gent, Belgium

${ }^{2}$ Department of Plant Systems Biology, VIB, 9052 Gent, Belgium

${ }^{3}$ Department of Plant Biotechnology and Bioinformatics, Ghent University, 9052 Gent, Belgium

${ }^{4}$ Institute of Plant Biotechnology Outreach-VIB, Incubation and Innovation Center-Ghent University, 9052 Gent, Belgium

Corresponding author: Blancke, S. (st.blancke@gmail.com).

Keywords: Genetically modified organisms - public opposition - intuitive mind - cultural attraction 
1 Public opposition to genetically modified organisms (GMOs) remains strong. By contrast,

2 studies demonstrate again and again that GM crops make a valuable contribution to the

3 development of a sustainable type of agriculture. The discrepancy between public opinion

4 and the scientific evidence requires an explanation. We argue that intuitive expectations

5 about the world render the human mind vulnerable to particular misrepresentations of

6 GMOs. We explain how the involvement of particular intuitions accounts for the

7 popularity, persistence and typical features of GM opposition and tackle possible

8 objections to our approach. To conclude, we discuss the implications in science education,

9 science communication and the environmental movement. 


\section{Explaining public opposition to GMOs}

12 Concerns about health, environmental and socio-economic hazards have resulted in a strong

13 public opposition to genetically modified organisms (GMOs) [1-3]. These worries tend to have a

14 large impact on national and international policies. For instance, in India, the government 15 suspended the culture of Bacillus thuringiensis-engineered Solanum melongena (Bt brinjal), 16 despite the initial approval for commercialization [4]. In Europe, the lack of public support for 17 GMOs has led to a de facto moratorium within the European Union on new GM crops from 1999 18 to 2004 and has steered the development of an extremely strict and expensive regulatory 19 framework concerning the import and cultivation of GM crops [5]. In Africa and Asia, the resistance to GMOs has had tragic consequences, costing thousands of lives [6, 7].

However, research shows that cultivation of GM crops does not pose any specific health or environmental risks, but instead can bring benefits to local farmers [8-11]. The reason for the discrepancy between public opinion and scientific evidence needs clarification. Some people suggest that post-Christian beliefs or romantic notions of nature are responsible, whereas others blame the lack of direct benefits for Western consumers $[6,12,13]$. These accounts are definitely on the right track. Nonetheless, they fail to explain why opposition also occurs in non-Christian cultures, why people do not reject every technology that brings no immediate benefits or why people prefer romantic views in the first place.

Here, we suggest a cognitive approach to account for the opposition to GMOs. In other words, we use ideas from the cognitive sciences, evolutionary psychology and cultural attraction to rationalize the popularity and typical features of this phenomenon. We argue that intuitions and emotions make the mind highly susceptible to particular negative representations of GMOs. 
33 We suggest ways to rectify the current situation and improve science education and 34 communication.

\section{An intuitive understanding of GMOs}

Although generally we feel as if we control willfully what we think and do, much of our thinking depends on intuitions, of which the working largely stays below the radar of conscious awareness [14]. Among other things, these intuitions, which evolved in response to particular adaptive situations, automatically shape expectations about the world or induce reflexive risk

42 assessments [15]. Under ecologically relevant conditions, these intuitions tend to generate 43 rational responses [16], but, when confronted with abstract and complex situations, these 44 intuitions tend to break down [17]. For instance, people are more easily scared by spiders than by 45 cars, although in modern society the number of mortal car accidents is much higher [18]. As to 46 our understanding of the world, cognitive predispositions can result in deeply engrained biases 47 that, if not dealt with by education, lead to persistent resistance to contra-intuitive scientific 48 theories in adulthood. Dualist intuitions, for instance, make it difficult to accept that mental 49 states result from physical processes [19]. Nevertheless, our thinking relies on at least two types 50 of reasoning processes. Besides the fast and automatic intuitions described above, humans can 51 resort to an effortful and reflective type of reasoning that allows them to consciously evaluate 52 and relate different information types [14, 20, 21]. By exercising this reflective capability and 53 thanks to the development and use of social and epistemic methods, tools and practices, scientists 54 have been able to tweak and build on their intuitions and, thus, to gain a more objective and 55 scientific understanding of the world [22-24]. 
The intuitive mind is not well equipped to address intricate questions, such as "What is

57 biotechnology?", "How does it work?" and, most importantly, "Is it dangerous?" The ability to

58 understand such issues and, hence, to have a subsequent objective and rational judgment requires

59 an important effort and, even then, the mind is still liable to relapse into biased thinking. Lay

60 people are often unable or are simply not interested in investing large amounts of time and

61 energy to acquire a profound grasp of complex technologies. Therefore, when lay people are

62 confronted with and have to evaluate information about GMOs and the risks involved, they will

63 predominantly rely on their intuitive mind. As a result, lay people tend to prefer GMO

64 representations that are most in line with their intuitive expectations, because these are easier to

65 understand and remember. Anti-GMO groups have successfully tapped into people's intuitions to

66 promote their cause, thus making their campaign highly attractive to the human mind [Box 1].

67 Below, we explore which intuitions make people vulnerable to GMO antagonism and

68 show how our approach explains the popularity, persistence and typical features of the GMO

69 hostility and also briefly counter some objections that might be raised. Finally, the implications

70 for science education, communication and the environmentalist movement are discussed.

71

72 The intuitive appeal of anti-GMO representations

$73 \quad$ Folk biology

74 The human mind intuitively understands how the biological world functions. One constituent of 75 this folk biology is psychological essentialism [25] that amounts to the belief that organisms hold 76 an unobservable, immutable core determining their identity and, thus, their development and

77 behavior. Psychological essentialism makes sense evolutionarily, because it allows individuals to 78 categorize automatically the biological world. As such, valuable information becomes 
79 immediately available, enabling apt responses to living entities in the environment. For instance,

80 when one is confronted with a tiger, the immediate realization that one is coping with a specimen

81 of the category "tiger" and, thus, that with its mighty claws and sharp fangs it might catch and

82 eat its prey, is a more adaptive reaction than to reassess each and every encountered stripy feline

83 [26]. Nevertheless, in spite of the obvious adaptive rationality of this cognitive predisposition,

84 psychological essentialism regularly interferes with a scientifically informed biological

85 understanding [27]. Notoriously, it impedes people's understanding of basic aspects of

86 evolutionary theory, but it also affects people's comprehension of GMOs, primarily because they

87 interpret DNA as the essence of organisms [28]. In a United States survey, more than half of the

88 respondents did not reject the idea that tomatoes whose genome had been modified to insert the

89 DNA of cat fish would taste like fish [29]. Apparently, people assumed that the fish's essence

90 had been introduced into these tomatoes, including a fishy taste. That people systematically

91 prefer cisgenic over transgenic organisms provides another indication of an essentialist bias [3].

92 In their campaigns, opponents of GMOs explicitly appeal to these essentialist intuitions by

93 distributing edited images of tomatoes with fish tails or by claiming that biotech companies

94 insert scorpion DNA elements into corn (Zea mays) to produce crispy corn flakes. The notion

95 that growing GM crops with herbicide tolerance will promote so-called superweeds falls back to

96 the same misconception that a weed can be characterized by a single gene. On the contrary,

97 typical weed characteristics, such as withstanding harsh environments, competing for light, water

98 and minerals and fast reproduction are the result of the interplay of numerous genes.

99

100

Teleological and intentional intuitions 
101 Another aspect of the intuitive mind that affects people's preferences for particular GMO 102 representations and the perception of the risks involved are teleological and intentional 103 intuitions. These intuitions tend to translate in religious beliefs, but they can also contribute to a 104 quasi-religious view on nature [30, 31]. Indeed, large parts of Europe, where the resistance 105 against GM food is strong, are highly secular. In the cognitive science of religion, religion is 106 commonly assumed to be a byproduct, generated by the peculiarities of our mental make-up that 107 includes essentialist thinking, but that is also highly receptive to the feeling that the world has 108 been designed for a particular purpose [32-35]. This design illusion has effectively been 109 debunked by evolutionary theory, but the mix of essentialist, teleological and intentional biases 110 continues to allure a lot of people in believing that a certain order exists in nature that should not 111 be meddled with. Indeed, genetic engineering is considered the opposite of "natural" [3, 36].

112 GMO opponents accuse scientists who produce transgenic plants of "playing god" and condemn 113 their acts as "against nature". Biotech food is often referred to as 'Frankenfood', suggesting that, 114 just as with Mary Shelley's artificial creature, the technology will escape the control of the 115 haughty scientists and result in horrific environmental doom scenarios.

\section{Emotions}

118 A category of mental features that particularly interferes with people's risk assessment of GMOs 119 are emotions. Disgust is especially important in this context. Particularly, revulsion may 120 influence the reactions to GMOs because people object more to GM food than to GMOs 121 developed for other applications [37]. Disgust evolved probably in response to adaptive 122 problems related to pathogen and poison avoidance [38-40]. The evolutionary rationale explains 123 why the emotion is on a hair trigger: To forego a nutritious meal because it is erroneously 
124 considered toxic or contaminated is potentially far less harming than to consume spoiled food

125 under the misguided assumption that it is perfectly edible [40]. Hence, distaste can be elicited by

126 food that is completely innocuous. Indeed, food taboos offer clear examples of disgust regulated

127 by cultural conventions, often involving meat derived from animals that are fit for human

128 consumption, but considered vile and dirty. In experiments, scientists induce revulsion by

129 presenting orange juice stirred with a sterilized cockroach or dog feces-like shaped caramelized

130 biscuit spread [41]. In the case of GM food, feelings of disgust possibly arise because of

131 psychological essentialism by which people intuitively interpret gene modification as an

132 unwarranted and contaminating intervention into the organism's essence, rendering the organism

133 impure and, therefore, no longer consumable. The effect will probably be enhanced when the

134 introduced DNA comes from a different species, or a species that is considered dirty. Anti-GMO

135 activists bombard the public with edited images that imply that GM foods cannot be trusted, such

136 as tomatoes with syringes or suspiciously blue biotech strawberries amid fresh red ones. Bt crops

137 are described as poisonous and instigate the fear that biotech crops will "contaminate" the

138 surrounding environment. Moreover, disgust also affects our moral judgment [38, 40, 42].

139 Hence, the emotion incites people to condemn not only the GM food itself, but also the

140 producers and developers of GM products as immoral. Linking socio-economic abuses to GM

141 products has become today's major focus of the anti GMO critique. To trigger moral disgust,

142 stories are brought up of big multinationals that chain farmers to ruthless contracts and patents or

143 even push resource-poor farmers into debt and suicide after they have been "seduced" to buy the

144 'killer' seeds. Plant biotech research institutes are pictured as a scientific community that burns

145 tax money while becoming totally dependent on research contracts with the big industry. The

146 current socio-economic implantation of GM technology into agriculture merits further analysis, 
147 because this issue raises important questions about the place and role of science in our complex

148 society. For instance, how should science relate to industry? Nevertheless, the current situation is

149 certainly not as black-and-white as activists pertain, and it is plainly wrong to call a single

150 breeding technology the cause of these complex issues.

152 How the opposition to GMO takes (and does not take) shape

154 Some representations are more popular than others. The popularity of a representation is 155 determined by the relevance of the information it purveys. Whether information is relevant 156 depends on its ability to capture attention and the ease by which the mind can process it. The 157 more information is in line with our intuitive expectations, the easier it is apprehended, 158 remembered and, thus, communicated. As intuitions are universally shared, appropriate 159 representations stand a greater chance of becoming widely distributed and culturally stable. At 160 the population level, an outline emerges in which representations converge into and stabilize 161 around hypothetical points, called cultural attractors [43, 44]. This pattern of attraction also 162 occurs in the case of the GMO opposition. The negative representations produced by anti-GMO 163 activists happen to reflect essentialist and intentional understandings of nature and suggest 164 contamination, hence, becoming highly salient to the corresponding intuitions (Figure 1). Due to 165 their aggregated relevance, these depictions will tend to outcompete the demonstrations of 166 scientists and other experts that require an enhanced cognitive effort. As such, the anti GMO 167 campaign has been extremely successful, not only to the surprise of scientists, but also of the 168 instigators themselves [45]. 
The preferential adoption of negative GMO representations takes place reflexively, 170 instantaneously, and largely under the radar of conscious awareness. However, the resulting 171 negative affect is consciously registered and, consequently, prompts people to justify their

172 feelings. A form of motivated reasoning emerges, in which arguments become highly prominent 173 that are applicable equally to other technologies, but are suddenly ignored. The alleged 174 unnaturalness of genetic engineering or the involvement of multinationals can just as easily be 175 applied against medical biotech applications, but only seem relevant in the case of GMOs. Other 176 arguments make sense because they are attuned to particular components of the mind's intuitive 177 appraisal. To a mind that is primed with feelings of disgust, it seems evident that GMOs can 178 provoke sickness or contaminate the environment. [Box 2]

179 Nevertheless, intuitions interact with other sensitivities and with the cultural 180 environment. For instance, people who may reap direct and considerable benefits from the 181 development and commercialization of GM products will become apt to adopt more positive 182 viewpoints. Moreover, they may trust information sources, such as scientific reports that 183 demonstrate that GMOs are safe and even beneficial. As such, the human mind is not 184 predetermined to think that GMOs are poisonous, disgusting or unnatural. However, once these 185 negative representations become culturally available, for instance, because of intense 186 campaigning by environmental groups or lack of any strong cultural counterforces, the human 187 mind will be highly susceptible to them. Furthermore, because cultural attraction addresses 188 statistical effects, we can expect intra-group varieties in the adoption of negative representations 189 of GMOs. In a culture that predominantly opposes GMOs, members will also be present that are 190 pro, and vice versa. Indeed, the opposition to GMOs is not everywhere as strong as it is in 191 Europe, although it is more common than people tend to think. 


\section{Concluding remarks and implications}

194 The human mind comprises evolved intuitions that shape and constrain cultural preferences. In 195 the case of GMOs, folk biology, religious intuitions, and emotions, such as disgust, leave the 196 mind readily seduced by representations of GMOs as abnormal or toxic. By pointing out how 197 public aversion to GMOs thrives on such preferences, it is understandable why people continue 198 to resort systematically to concerns about GMOs that are scientifically unsubstantiated. With 199 such a perspective that is not intended to characterize public worries in general as irrational, we 200 hope that a cognitive understanding can contribute to a better insight into and perhaps a more 201 lenient attitude toward the public's anxieties. Additionally, we expect to open up the eyes of 202 those who reject GMOs as a whole and wish to let them realize that their concerns arise from 203 sources that cannot be trusted prima facie and that the risks and benefits can only be assessed on 204 a case-by-case basis, depending on the result and not the process [46].

205 Education can, at least to a certain extent, abate the intuitive appeal of negative GMO 206 representations. Instruction of young people about biotechnology and its implications will 207 require educational strategies that specifically target and tweak intuitive modes of thinking. 208 However, this method of immunizing minds is certainly not foolproof. Intuitive thinking remains 209 a trap, even to the minds of experts. At the same time, scientists and institutions, companies and 210 governments that communicate about GMOs and their potential risks can also appeal to the 211 intuitive mind. Although GMOs are at a disadvantage because they are commonly associated 212 with unnaturalness and trigger disgust, emphasis on the benefits would effectively induce 213 sympathy [37, 47]. Even though individual people may not always experience a personal 214 advantage by purchasing and/or consuming GMOs, it will certainly help to inform the public 
215 that, e.g., (i) Bt corn contains less mycotoxins and is thus healthier than conventional maize [48],

216 (ii) herbicide-resistant crops require less tilling and, thus, improve the soil quality, (iii) Bt crops

217 enhance the insect biodiversity [49], (iv) biotech crops help reduce poverty in India [50], and so 218 on.

219 Finally, our approach suggests that people who are genuinely concerned about the 220 environment may intuitively adopt strategies that have the opposite impact on what they set out 221 to achieve. GMOs can be a formidable tool in the realization of a sustainable form of agriculture. 222 By leading people to choose the wrong adversaries and to urge policy makers to take counter223 effective measures, negative GMO representations may indeed exert a fatal attraction.

\section{Acknowledgments}

226

227 We thank Dr. Martine De Cock for help in preparing the manuscript and Thom Scott-Phillips for 228 the helpful remarks. This work was supported by the Ghent University Multidisciplinary 229 Research Partnership "Sustainable BioEconomy” (Project 01MRB510W) and Ghent University 230 grant BOF13/24J/089.

231

\section{References}

233

2341 Jayaraman, K. and Jia, H. (2012) GM phobia spreads in South Asia. Nat. Biotechnol. 30, $235 \quad 1017-1019$

2362 Arthur, G.D. (2011) Benefits and concerns surrounding the cultivation of genetically 237 modified crops in Africa: The debate. Afr. J. Biotechnol. 10, 17663-17677 
2383 Gaskell, G. et al. (2010) Europeans and Biotechnology in 2010: Winds of Change?

239 (Eurobarometer Survey Series, No. 7; Report EUR 24537), Publications Office of the

$240 \quad$ European Union

2414 Anonymous (2010) India bows to negative sentiments on Bt Brinjal. NatureIndia, 242 http://www.natureasia.com/en/nindia/article/10.1038/nindia.2010.10

2435 Devos, Y. et al. (2006) The interplay between societal concerns and the regulatory frame 244 on GM crops in the European Union. Environ.l Biosafety Res. 5, 127-149

2456 Paarlberg, R. (2008) Starving for science. How Biotechnology is Being Kept out of $246 \quad$ Africa. Harvard University Press

$247 \quad$ Wesseler, J. and Zilberman, D. (2014) The economic power of the Golden Rice 248 opposition. Environ. Dev. Econ. 19, 724-742

2498 Mannion, A.M. and Morse, S. (2012) Biotechnology in agriculture: Agronomic and 250 environmental considerations and reflections based on 15 years of GM crops. Prog. Phys. 251 Geogr. 36, 747-763

2529 Qaim, M. and Kouser, S. (2013) Genetically modified crops and food security. PLoS $253 \quad$ ONE 8, e64879

25410 Snell C. et al. (2012) Assessment of the health impact of GM plant diets in long-term and 255 multigenerational animal feeding trials: A literature review. Food Chem. Toxicol. 50, $256 \quad 1134-1148$

25711 Brookes, G. and Barfoot, P. (2012) The income and production effects of biotech crops 258 globally 1996-2010. GM Crops Food: Biotechnol. Agric. Food Chain 3, 265-272

25912 Silver, L.M. (2006) Challenging Nature. The Clash between Biotechnology and 260 Spirituality. HarperCollins 
26113 Fresco, L.O. (2013) The GMO Stalemate in Europe. Science 339, 883-883

262 Kahneman, D. (2011) Thinking Fast and Slow. Farrar, Straus and Giroux

26315 Tooby, J. and Cosmides, L. (1992) The biological foundations of culture. In The Adapted 264

265 Mind. Evolutionary Psychology and the Generation of Culture (Barkow, J. et al., eds), pp. 19-136, Oxford University Press

26616 Gigerenzer, G. (2008) Rationality for Mortals. How People Cope with Uncertainty. 267 Oxford University Press

26817 Haselton, M.G., Nettle, D., and Andrews, P.W. (2005) The evolution of cognitive bias. In 269 The Handbook of Evolutionary Psychology (Buss, D.M., ed), pp. 724-746, John Wiley \& 270 Sons

27118 Öhman, A. and Mineka, S. (2001) Fears, phobias, and preparedness: Toward an evolved 272 module of fear and fear learning. Psychol. Rev. 108, 483-522

27319 Bloom, P. and Weisberg, D.S. (2007) Childhood origins of adult resistance to science. 274 Science 316, 996-997

27520 Sloman, S.A. (1996) The empirical case for two systems of reasoning. Psychol. Bull. 119, $276 \quad 3-22$

27721 Evans, J.S.B.T. (2010) Thinking Twice. Two Minds in One Brain. Oxford University $278 \quad$ Press

27922 Haack, S. (2003) Defending Science - Within Reason. Between Scientism and Cynism. $280 \quad$ Prometheus Books

28123 Goldman, A.I. (1999) Knowledge in a Social World. Clarendon Press

28224 Heintz, C. (2013) Scaffolding on core cognition. In Developing Scaffolds in Evolution, 283 Culture and Cognition (Caporael, L. et al., eds), pp. 209-228, MIT Press 
28425 Gelman, S.A. (2004) Psychological essentialism in children. Trends Cogn. Sci. 8, $285 \quad 404-409$

28626 Barrett, H.C. (2001) On the functional orgins of essentialism. Mind \& Society 2, 1-30

28727 Shtulman, A. and Schulz, L. (2008) The relation between essentialist beliefs and 288 evolutionary reasoning. Cogn. Sci. 32, 1049-1062

28928 Gelman, S.A. and Rhodes, M. (2012) "Two-thousand years of stasis": How psychological 290 essentialism impedes evolutionary understanding. In Evolution Challenges. Integrating Research and Practice in Teaching and Learning about Evolution (Rosengren, K.S. et 292 al., eds), pp. 3-21, Oxford University Press

29329 Hallman, W.K. et al. (2004) Americans and GM Food: Knowledge, Opinion and Interest 294 in 2004 (Food Policy Institute Publication RR-1104-007), The State University of New 295 Jersey

29630 Kelemen, D. and Rosset, E. (2009) The human function compunction: Teleological 297 explanations in adults. Cognition 111, 138-143

29831 Kelemen, D., Rottman, J., and Seston, R. (2013) Professional physical scientists display 299 tenacious teleological tendencies: Purpose-based reasoning as a cognitive default. J. Exp. Psychol.: General 142, 1074-1083

30132 Barrett, J.L. and Lanman, J.A. (2008) The science of religious beliefs. Religion 38, 302 $109-124$

30333 Boyer, P. (2001) Religion Explained. The Evolutionary Origins of Religious Thought. 304 Basic books

30534 Kelemen, D. (2004) Are children "intuitive theists"? Reasoning about purpose and design 306 in nature. Psychol. Sci. 15, 295-301 
30735 Järnefelt, E. et al. (2015) The divided mind of a disbeliever: Intuitive beliefs about nature as purposefully created among different groups of non-religious adults. Cognition, in press.

31036 Rozin, P. et al. (2012) European and American perspectives on the meaning of natural. Appetite 59, 448-455

31237 Savadori, L. et al. (2004) Expert and public perception of risk from biotechnology. Risk 313 Anal. 24, 1289-1299

31438 Tybur, J.M. et al. (2013) Disgust: Evolved function and structure. Psychol. Rev. 120, 315 65-84

31639 Curtis, V. et al. (2011) Disgust as an adaptive system for disease avoidance behaviour.

317 Philos. Trans. R. Soc. B-Biol. Sci. 366, 389-401

$31840 \quad$ Kelly, D. (2011) Yuck! The Nature and Moral Significance of Disgust, MIT Press.

31941 Rozin, P. et al. (1986) Operation of the laws of sympathetic magic in disgust and other 320 domains. J. Pers. Soc. Psychol. 50, 703-712

32142 Haidt, J. (2001) The emotional dog and its rational tail: A social intuitionist approach to 322 moral judgment. Psychol. Rev. 108, 814-834

32343 Sperber, D. (1996) Explaining Culture: A Naturalistic Approach. Blackwell

32444 Claidière, N. et al. (2014) How Darwinian is cultural evolution? Philos. Trans. R. Soc. B325 Biol. Sci. 369, 20130368

32645 Lynas, M. (2011) The God Species. Saving the Planet in the Age of Humans. National 327 Geographic

32846 Ammann, K. (2014) Genomic Misconception: a fresh look at the biosafety of transgenic 329 and conventional crops. A plea for a process agnostic regulation. New Biotech. 31, 1-17 
33047 Rommens, C.M. (2010) Barriers and paths to market for genetically engineered crops. $331 \quad$ Plant Biotechnol. J. 8, 101-111

$33248 \mathrm{Wu}$, F. (2006) Mycotoxin reduction in Bt corn: Potential economic, health, and 333 regulatory impacts. Transgenic Res. 15, 277-289

33449 Ammann, K. (2005) Effects of biotechnology on biodiversity: herbicide-tolerant and 335 insect-resistant GM crops. Trends Biotechnol. 23, 388-394

33650 Subramanian, A. and Qaim, M. (2010) The impact of Bt cotton on poor households in 337 rural India. J. Dev. Stud. 46, 295-311

33851 Blancke, S. and De Smedt, J. (2013) Evolved to be irrational? Evolutionary and cognitive 339 foundations of pseudosciences. In Philosophy of Pseudoscience: Reconsidering the 340 Demarcation Problem (Pigliucci, M. and Boudry, M., eds.), pp. 361-379, University of $341 \quad$ Chicago Press

34252 Boudry, M. et al. (2015) What makes weird beliefs thrive? The epidemiology of 343 pseudoscience. Philos. Psychol., in press (10.1080/09515089.2014.971946)

34453 Boyer, P. and Peterson, M.B. (2011) The naturalness of (many) social institutions. J. Inst. $345 \quad$ Econ. 8, 1-25

34654 Blancke, S. et al. (2014) From ends to causes (and back again): The paradox of natural $347 \quad$ selection. Sci. Educ. 23, 793-808 
350 Box 1 - The role of intuitions in cultural domains

351 The opposition to GMOs is not the only complex of beliefs that piggybacks upon folk intuitions.

352 For instance, religious beliefs are typically explained in terms of the appeal they exert on 353 ordinary human cognition that includes essentialist reasoning, a hyperactive agency detection 354 system and an intuitive theory of mind [32-34]. Also pseudoscience taps into these and other 355 intuitions, a trait that can persist in the face of scientific discovery. Creationism is anchored in 356 essentialist, teleological and intentional intuitions and creationists even explicitly call upon these 357 intuitions to bolster their case [51]. Pattern recognition leads us to over-detect correlations and 358 causation, leaving the mind susceptible to all kinds of superstition, such as fear of black cats or 359 walking under ladders. Furthermore, medical pseudoscience owes its success largely to placebo 360 thinking by which people who are ill get better merely by thinking that they will [52]. In fact, 361 intuitions affect a wide range of social and cultural domains, such as social institutions and the 362 development of science [52-54]. The cases of GMO opposition and pseudoscience demonstrate 363 that intuitions can even favour the distribution of beliefs that are flatly contradicted by evidence. 
365 Box 2 - Reasonable doubt?

366 The influence of intuitions highly accounts for the typical features and popularity of the 367 opposition to GMOs. Moreover, many of the arguments levelled against GMOs articulate 368 concerns that clearly arise from intuitions and emotions. Other arguments only become relevant 369 in the context of GMOs because people seek ways to rationalize their intuitively felt resistance. 370 In turn, some of these arguments tap into and exploit moral concerns about fairness (such as 371 multinationals exploit small farmers) and environment (such as GMOs kill butterflies) that can 372 consequently become amplified with intuitively appealing allegations about sickness and 373 unnaturalness. Arguments against GMOs sound even more convincing when they come from an 374 allegedly trustworthy source, such as an environmentalist organization or a friend, or when they 375 are popular among the social group one wants to be part of. Hence, people oppose GMOs for 376 reasons other than mere intuitive appeal, such as trust and conformity. Are there any reasonable 377 scientific worries to account for the opposition against GMOs? Some reports and studies have 378 claimed that GMOs per se badly affect health, environment, and small farmers in developing 379 countries. These studies, however, turned out to be unsubstantiated. Anti-GMO activists continue 380 to refer to these studies. As such, they cloak their arguments under a scientific veil, thus 381 exploiting the cultural authority of science. In this regard, the opposition to GMOs resembles 382 pseudosciences, such as "scientific" creationism and homeopathy that mimic science in an 383 attempt to gain respectability [52]. At the same time, anti-GMO activists also adopt 384 pseudoscientifical tactics to undermine the authority and autonomy of the science that contradicts 385 their claims, for instance by overstating the impact of industry on plant sciences. As a result, 386 people may wrongly assume that there are good scientific reasons to oppose GMOs. 
387 For sure, our cognitive analysis does not render every public concern unfounded a priori. Some 388 of these apprehensions can be legitimate. For instance, herbicide resistance in weeds has indeed 389 become a problem in areas, such as the United States and Argentina where farmers have over390 relied on a single herbicide-resistant crop that was tolerant to glyphosate. However, these 391 concerns are typically unrelated to the technology of genetic modification, but result from 392 unsound agricultural practices and policy that also can cause problems in the case of 393 "conventional" crops. Moreover, whether a particular GM application has unwanted effects 394 needs to be tested on a case-to-case basis, thereby focusing not on the technology, but on the 395 resulting product. 


$\left.\left.\begin{array}{c}\text { Essentialism } \\ \begin{array}{c}\text { Teleological and intentional } \\ \text { thinking } \\ \text { Disgust }\end{array} \longrightarrow \begin{array}{c}\text { DNA as the essence } \\ \text { of an organism } \\ \text { Nature as a beneficial } \\ \text { agent or process } \\ \text { Genetic modification } \\ \text { as contamination }\end{array} \rightarrow \begin{array}{c}\text { Fish-tomato; breach of } \\ \text { species boundaries }\end{array} \\ \text { "Unnatural", "playing God" } \\ \begin{array}{c}\text { GMOs cause diseases and } \\ \text { sterility; "contamination" of } \\ \text { fields and food/feed }\end{array}\end{array}\right\} \begin{array}{c}\text { GMOs are } \\ \text { dangerous and } \\ \text { immoral }\end{array}\right\}$

398

399 Figure 1. Unsubstantiated negative representations of GMOs tapping into intuitive preferences 